\title{
Chloroplast signal length requirement reflects the outer membrane and TOC complex dimension
}

\section{BODO TILLMANN ${ }^{1,4}$ \\ OLIVER MIRUS ${ }^{1}$ \\ ENRICO SCHLEIFF1-3 \\ ${ }^{1}$ Molecular Cell Biology of Plants, Goethe University, Max-von-Laue-Str. 9, 60438 Frankfurt, Germany \\ ${ }^{2}$ Cluster of Excellence Frankfurt; Goethe University, Max-von-Laue-Str. 9, 60438 Frankfurt, Germany \\ ${ }^{3}$ Buchmann Institute for Molecular Life Sciences; Goethe University, Max-von-Laue-Str. 9 , 60438 Frankfurt, Germany \\ ${ }^{4}$ TRON - Translational Oncology at the University Medical Center of the Johannes Gutenberg University Mainz GmbH}

\section{Correspondence:}

Enrico Schleiff

Goethe University, Molecular Cell Biology of Plants, Max-von-Laue-Str. 9-N200/R3.02, 60438 Frankfurt, Germany:

e-mail: schleiff@bio.uni-frankfurt.de

Key words: Protein translocation, targeting signal, transit peptide, chloroplast, TOC translocon

\begin{abstract}
Background and Purpose: The evolution of an efficient preprotein targeting and translocation system was a central prerequisite for the endosymbiotic integration of $\alpha$-proteobacteria and cyanobacteria as cellular organelles. Today, it is widely accepted that during evolution most (pre-)proteins destined for these two organelles were equipped with an $N$-terminal targeting signal for localization. While multiple modes of evolution of these extensions are currently discussed, all evolved signals serve the same functionforming a signal for targeting to the correct organelle and translocation across both membranes. We aimed to generalize the current idea for the length requirement of the $N$-terminal extension for efficient translocation.
\end{abstract}

Methods: To explore translocation efficiency in vivo we used protoplasts isolated from different plant sources. We compared the behavior of native and artificial precursor proteins in this plant cell system by fluorescence microscopy.

Results: We demonstrate that the minimal length of the $N$-terminal amino acid stretch in a loosely folded conformation of a precursor of a chloroplast protein is about 60 amino acid residues. This amino acid stretch in a loosely folded state is prerequisite that a preprotein can traverse the outer membrane in vivo.

Conclusion: We generalize the evidence that two distinct prerequisites framed the evolutionary process of development of targeting signals for chloroplast translocation. (i) The emerging signal had to be sufficiently distinct to signals existing for targeting to other cellular compartments. (ii) The $N$ terminal signal had to evolve with physico-chemical properties that serve both purposes: targeting and translocation. With respect to the latter, the length of the unfolded polypeptide is defined by the dimension of the translocon and the resulting distance between the cytosolically exposed receptors acting on the cis side of the membrane and the molecular machinery energizing translocation acting in trans - in the intermembrane space.

\section{INTRODUCTION}

The functional integrity of cellular compartments depends on mas1 sive protein transport through the cytosol and translocation across according membranes (1). Central for such processes are signals either encoded as amino acid extensions or as signatures within the mature part of the precursor proteins (preproteins; 2,3). For example, at least two signals have been described for targeting toward peroxisomes. One signal is positioned at the extreme $\mathrm{C}$-terminus of proteins targeted to
Received March 23, 2015

Revised April 14, 2015.

Accepted June 1, 2015. 
peroxisomes and was annotated as "peroxisomal targeting signal 1" (PTS1; 4). It consists of the tripeptide Ser-LysLeu (SKL) or conserved variants (5). A second signal for peroxisomal targeting is formed by an N-terminal polypeptide segment annotated as the "peroxisomal targeting signal 2" (PTS2, 4). This signal is cleaved off by processing peptidases upon translocation. In line, for targeting to mitochondria and chloroplasts a multitude of different signals has evolved (6), but N-terminal polypeptide extensions are by far most dominant.

Although the transit peptides of chloroplast-targeted proteins are discussed to be important for targeting and translocation, a common nature is hard to grasp. Transit peptides are enriched in uncharged residues at the Nterminus of the signal and in hydroxylated amino acids in general (7-9)). Many sequence motifs have been discussed, but the only experimentally validated and unchallenged motif is a pair of consecutive, positively charged amino acid residues required for preferential import into mature chloroplasts (10). The length of the cleavable part annotated as transit peptides is in the range of 10 to more than 150 amino acid residues, but more than $50 \%$ of the yet identified preproteins have transit peptides shorter than 50 amino acid residues $(11,12)$.

Various scenarios have been proposed with regard to transit peptide evolution (e.g. 13). For a subset of proteins it is assumed that existing signals for secretion have been recycled. Considering that the chloroplast protein translocation pore Toc75 originated from the outer membrane ß-barrel protein assembly factor Omp85 (e.g. 14) and the importance of a C-terminal phenylalanine or tryptophane residue for targeting to bacterial Omp85 (15), mutations of such signals to include aromatic amino acids might have caused an evolutionary advantage. Indeed, signals for translocation into the primitive plastid of Cyanophora paradoxa still contain a phenylalanine at their $\mathrm{N}$-terminus (16-21). In line with such scenario, the phenylalanine of a precursor protein from $C$. paradoxa enables the precursor protein to interact with a cyanobacterial Omp85 (22).

For proteins destined for the chloroplast stroma new signals had to evolve. Here, at least two scenarios are discussed: (i) a signal evolved by a process annotated as "exon shuffling" or (ii) the ancestral 5'UTR might have been used or modified to code for a signal (13). The proposal of the exon-shuffling is based on earlier observations that signal sequences of some chloroplast preproteins are encoded by three distinct exons (23-26). It is argued that in the course of evolutionary adaptation an intron loss might have occurred. The alternative scenario on 5'UTR retention was concluded from the analysis of the $\mathrm{O}$-acetylserine (thiol)-lyases (27). However, it was discussed that the evolutionary mode was also dependent on the fitting accuracy of the evolving signal and the translocon (13).

Translocation of precursor proteins across the outer envelope membrane is catalyzed by the translocon of the outer chloroplast membrane (TOC; 28,29$)$. The complex is composed of the two GTP-regulated receptors Toc34 and Toc159 and the pore-forming Toc75. In addition, it was shown that the Hsp90 receptor Toc64 dynamically associates with these proteins (30-32). Currently, at least three proteins are suggested to drive the transfer of the precursor from the TOC complex to the translocon of the inner chloroplast membrane (TIC; 28,29), namely Toc12 attached to the outer envelope in trans, Toc64 (33-35) and the intermembrane space-localized Tic22 (36-38). However, the mode of this transfer and of the subsequent translocation across the IMS is largely unknown.

In here, we analyzed the conservation of the transit peptide length requirement for protein translocation in vivo. This information is central to understand which energizing modules are involved in the process. In the past at least three different elements have been proposed: an energizing module at the cis side of the outer envelope membrane, one at the trans side of the outer envelope membrane and a third one in the stroma (e.g. 28,29). While the energizing mode at the cis side is attributed to GTP hydrolysis, the other two events discussed depend on ATPases required for successful translocation (6). In here, we document that the evolutionary pressure for chloroplast signal evolution is presented by the energizing modules at the trans side of the outer envelope membrane, because the minimal length of 60 amino acid residues of a loosely folded $\mathrm{N}$-terminal polypeptide stretch is only able to span the outer membrane.

\section{SUBJECT AND METHODS}

\section{Construct generation}

Constructs have been previously generated or created as previously described $(12,33)$ and corresponding amplified cDNA-fragments were ligated into pML94-GFP and pML94-GFP-SKL via Acc65I and BcuI (12) or via EcoRI or NcoI and XhoI into pML94-titin-GFP and pML94titin-GFP-SKL.

\section{Plant material, Protoplast isolation and transformation}

Sterile tobacco (Nicotiana tabacum cv. Petit Havana), tomato (Solanum lycopersicum cv. Moneymaker) and Arabidopsis thaliana (ecotype Columbia) plants were grown on soil or gelrite-solidified Murashige and Skoog (MS) medium supplemented with 30 or $20 \mathrm{~g} / \mathrm{L}$ sucrose, respectively. Tomato, tobacco and $A$. thaliana leaf mesophyll protoplasts were isolated from 4-6 week-old plants and transformed using the polyethylene glycol-mediated transformation protocol $(39,40)$. Generally, $10^{5}$ protoplasts were transformed with $20 \mu \mathrm{g}$ plasmid-DNA, if necessary the final amount of DNA was adjusted by addition of the plasmid pRT-Neo. Cells were incubated in light for $6 \mathrm{~h}$ at $26^{\circ} \mathrm{C}$ in light. 


\section{Microscopic analyses}

Intracellular localization of GFP fusion proteins in protoplasts was analyzed by fluorescence microscopy using a Leica SP5 confocal laser scanning microscope with a HCX PL APO lambda blue 63x NA 1.4 oil objective as in (12). GFP and chlorophyll fluorescence were excited at $488 \mathrm{~nm}$. The emission of GFP was recorded at 495 to 540 $\mathrm{nm}$ and of chlorophyll at 670 to $720 \mathrm{~nm}$.

\section{RESULTS}

\section{The efficiency of short transit peptides for chloroplast import in Nicotiana tabacum}

In a previous study the translocation competence of different pNTT1 (nucleotide triphosphate transporter 1) fusion proteins upon transient expression in tomato ( $\mathrm{So}$ lanum lycopersicum $\mathrm{cv}$. Moneymaker) were used to assess the minimal signal length requirement of 60 amino acid residues for chloroplast translocation (12). The constructs were based on the $27^{\text {th }}$ immunoglobulin domain of the human muscle protein titin (named titin hereafter) fused to GFP, previously used to investigate the preprotein translocation mode $(12,41,42)$. Thereby, the titin domain serves as common passenger domain that was shown to be tightly folded already during the targeting process. Unfolding of this passenger domain is prerequisite for translocation and requires pulling force of $200 \mathrm{pN}$ at the $\mathrm{N}$-terminus $(42,43,44)$. However, the minimal length of a signal stretch of 60 amino acids for in vivo import of a passenger protein was only documented for tomato so far. Consequently, we asked whether this rule is generally applicable.

At first we expressed the different pNTT1-based titinGFP fusion constructs (Figure 1a) in tobacco (N. tabacum cv. Petit Havana) protoplasts (Figure 1b). The localization of the preprotein was determined by confocal laser scanning microscopy analyses of GFP fluorescence distribution using the thylakoid derived chlorophyll derived autofluorescence as marker of chloroplast positioning. A cytosolic distribution of the GFP signal (Figure 1b, left) was observed upon expression of a construct harboring the 21 amino acid transit peptide of pNTT1 (Figure 1a, blue) extended by the subsequent amino acids of the mature domain (Figure 1a, red) to a final length of 50 residues fused C-terminally to titin (Figure 1a, black) and GFP (Figure 1a, green; tp(50)NTT1-titin-GFP). This confirms that 50 amino acid residues are not sufficient for translocation of the protein into chloroplasts. In contrast, extending the mature section as such that $60(\mathrm{tp}(60)$ NTT1-titin-GFP) or $70 \mathrm{~N}$-terminal amino acids residues of pNTT1 are present resulted in chloroplast-localized GFP fluorescence (tp(70)NTT1-titin-GFP; Figure 1b, middle and right). (a)
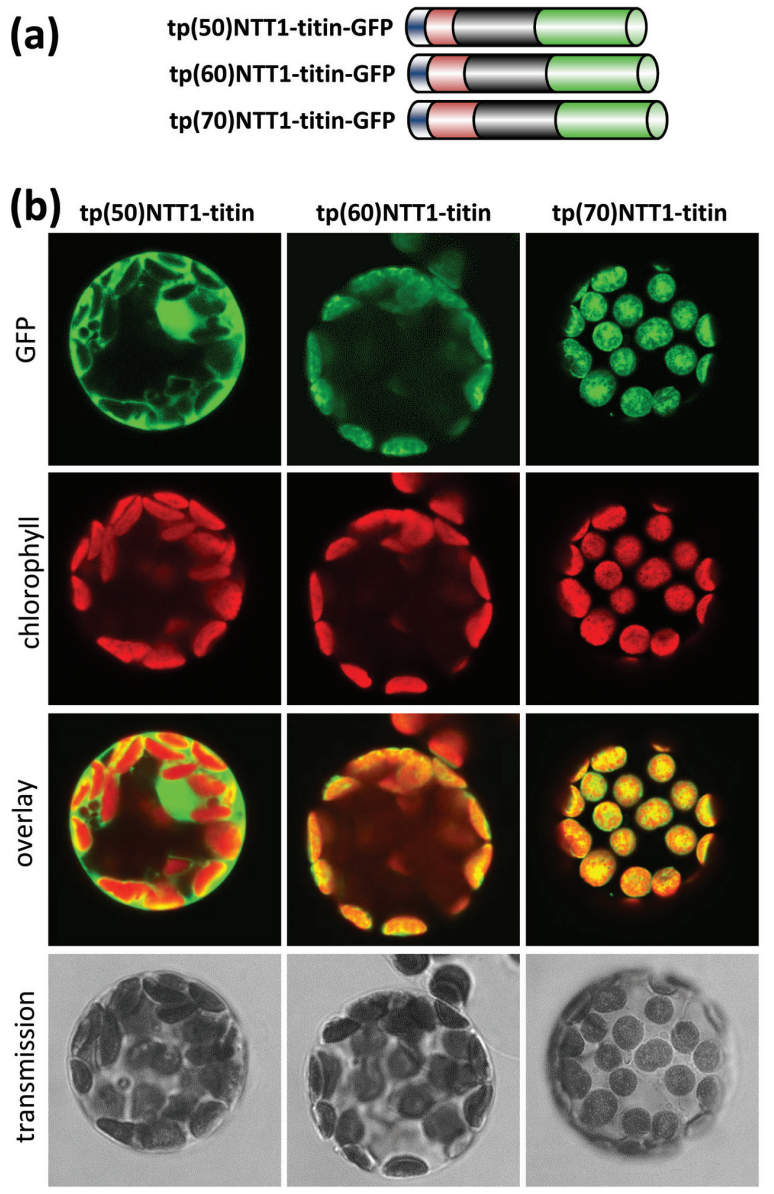

Figure 1. The signal length requirement for pNTT1 translocation in tobacco protoplasts. (a) The constructs used are shown as scheme. The transit peptide is shown in blue, the mature domain in red, the titin domain in black and the GFP domain in green. (b) Tobacco protoplasts were transformed with the constructs indicated on top and analyzed by CLSM inspection after 6 hours expression. The GFP signal, the chlorophyll auto-fluorescence signal, the overlay of GFP and chlorophyll signal and the signal in the transmission channel for representative images are shown.

To extend this observation, the first 50 amino acid residues of pRbl11 (precursor of chloroplast-localized rhomboid-like protein; 12,45 ) were fused to titin-GFP (tp(50)Rbl11-titin-GFP; Figure 2a). The construct was subsequently transformed into and expressed in $N$. tabacum protoplasts. The expression of this construct yielded a cytosolic GFP distribution as assessed by fluorescence microscopy (Figure 2b, left). In contrast, when the fulllength protein is fused to titin-GFP and expressed in $N$. tabacum protoplasts we observed a chloroplastic GFP signal surrounding the chlorophyll fluorescence (pRbl11titin-GFP; Figure 2b, right). The rim signal was expected, because pRbl11 has predicted envelope localization (45).

Next, we used the transit peptide of the precursor of the small subunit of RUBISCO (pSSU), which has a 
length of 56 amino acid residues. Expression of the fusion protein composed of the transit peptide fused to titin-GFP (Figure 3a) in N. tabacum protoplasts resulted in a dual localization of the fusion protein in the cytosol and chloroplasts (Figure 3b, left). This result is consistent with the one observed after expression of this construct in tomato protoplasts (12). In contrast, when the fulllength pSSU is fused to titin-GFP or GFP (pSSU-titinGFP, pSSU-GFP) and expressed in N. tabacum protoplasts, the encoded protein is effectively imported into chloroplast in tobacco as judged from the overlay between GFP and auto-fluorescence signal (Figure 3b, middle right).

\section{The efficiency of truncated transit peptides for chloroplast import in vivo}

So far the conclusion of the minimal length requirement is based on extending short transit peptides (Figures $1,2 ; 12,41)$. Thus, we aimed to confirm that the require-

\section{(a)}

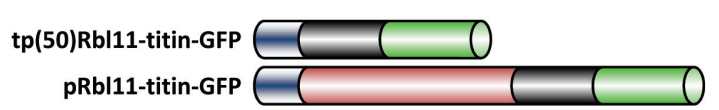

(b)

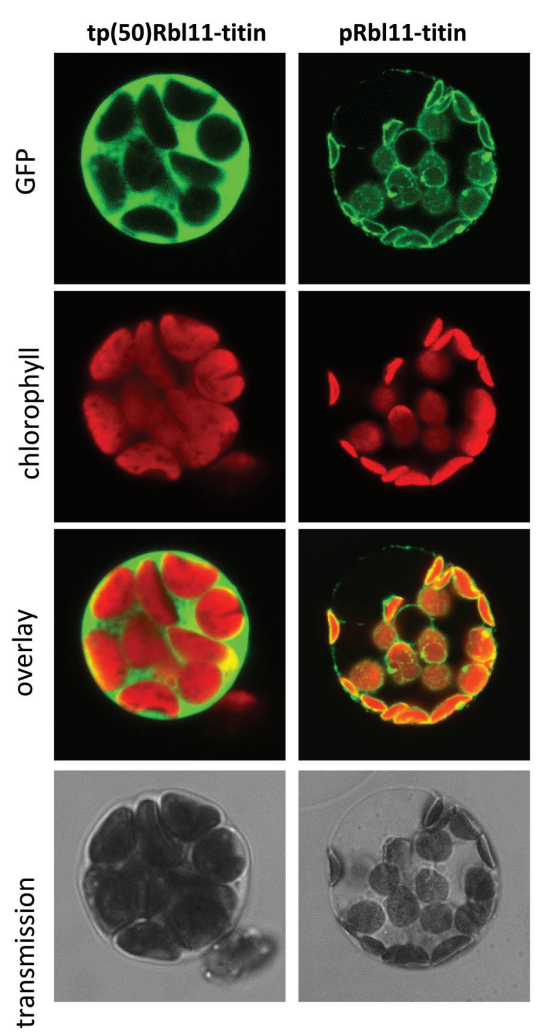

Figure 2. The signal length requirement for $p$ Rbl11 translocation in tobacco protoplasts. (a) The constructs used are shown as scheme as in Figure 1a. (b) Tobacco protoplasts were transformed with the constructs indicated on top and analyzed by CLSM inspection after 6 hours expression. The GFP signal, the chlorophyll auto-fluorescence signal, the overlay of GFP and chlorophyll signal and the signal in the transmission channel for representative images are shown.

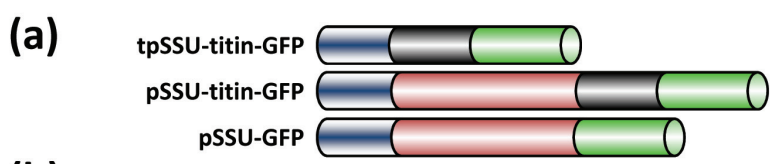

(b) pSSU-GFP
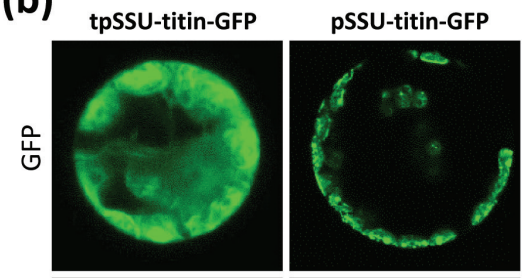

PSSU-GFP
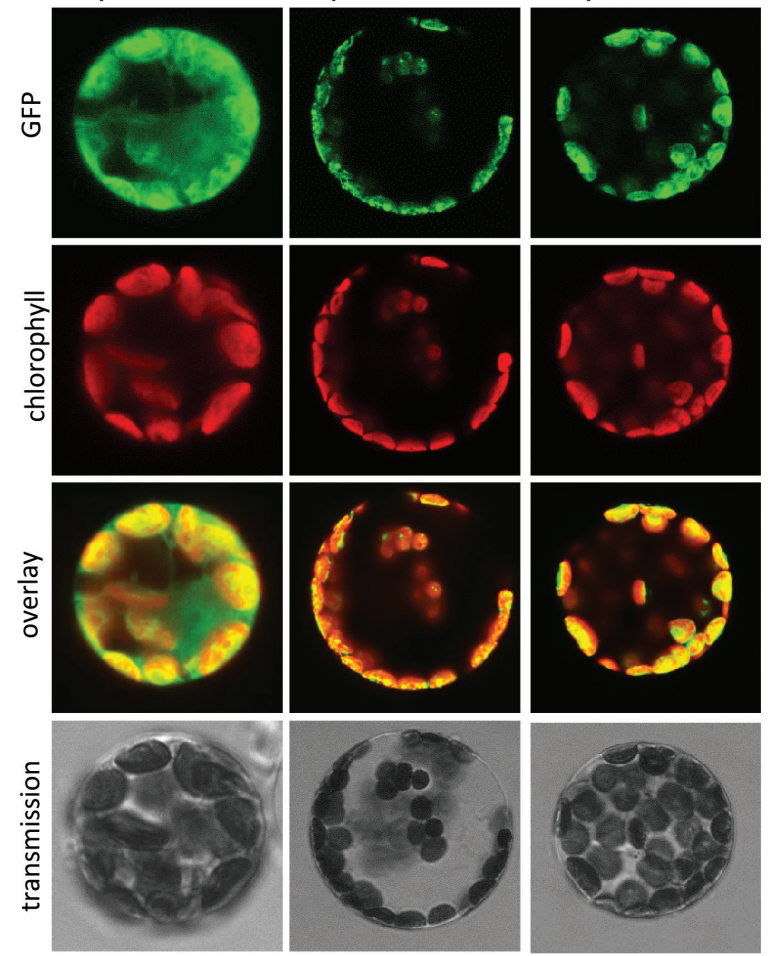

Figure 3. The signal length requirement for $p S S U$ translocation in tobacco protoplasts. (a) The constructs used are shown as scheme as in Figure 1a. (b) Tobacco protoplasts were transformed with the constructs indicated on top and analyzed by CLSM inspection after 6 hours expression. The GFP signal, the chlorophyll auto-fluorescence signal, the overlay of GFP and chlorophyll signal and the signal in the transmission channel for representative images are shown.

ment of a signal of 60 amino acids is also valid when a transit peptide of a larger size is truncated. To this end, we inspected a set of fusion constructs based on the transit peptide of pOE33 (precursor of the oxygen evolving complex subunit of $33 \mathrm{kDa}$ ). pOE33 contains a so-called bipartide transit peptide with a stromal signal (amino acid residues 1-30) and a thylakoid signal (amino acid residues 31-79). We fused N-terminal sections of the signal of 55, 60 and 65 amino acids, as well as the full-length transit peptide to titin-GFP (Figure 4a) to generalize the findings for pNTT1. Expression of tp(55)OE33-titin-GFP in tobacco (Figure $4 \mathrm{~b}$ ) or tomato (Figure $4 \mathrm{c}$ ) protoplasts revealed an exclusive cytosolic distribution of GFP (Figure $4 \mathrm{~b}, \mathrm{c}$; top panel). Thus, the pOE33-derived 55 amino acid residues are not sufficient to drive protein translocation into chloroplasts. While using tp(60)OE33-titin-GFP we observed a dual distribution of the GFP signal in the cytosol and in chloroplasts as judged from the GFP-fluores- 
cence overlay with the auto-fluorescence (Figure 4b,c; second panel). However, comparison between tobacco (Figure 4b) and tomato (Figure 4c) protoplasts revealed that the translocation efficiency in tomato is somewhat higher than in tobacco protoplasts, which might suggest that slight species-specific variations of the transit peptide length requirement exist. Moreover, the dual localization parallels the observation for tpSSU-titin-GFP (Figure 3b), which shows that the length requirement is also slightly dependent on the signal used.

As expected, using 65 amino acid residues (tp(65) OE33-titin-GFP) or the entire transit peptide of pOE33 (tpOE33-titin-GFP) we observed an exclusive localization of the GFP signal in chloroplasts as judged from the overlay with the auto-fluorescence (Figure 4b,c; third and fourth panel). Thus, we conclude that the observed signal length requirement does not dependent on the experimental strategy.

(a)

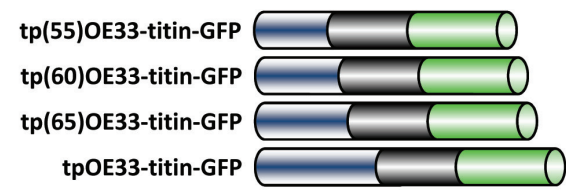

(b) GFP
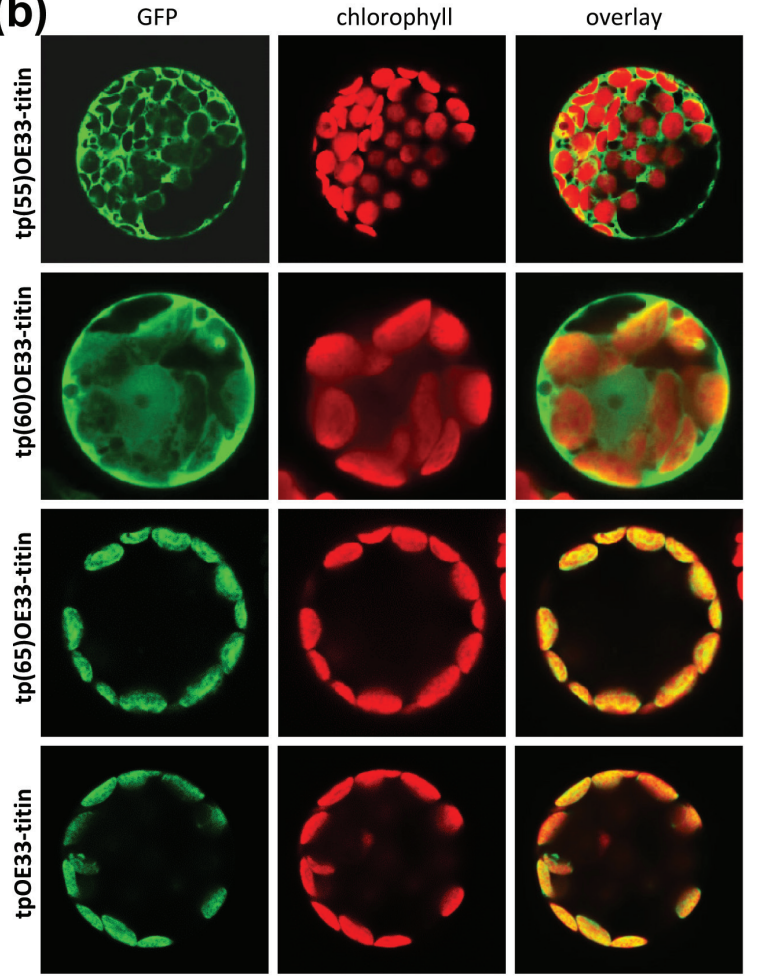

The transit peptide length requirement for chloroplast import is valid in A. thaliana

A. thaliana is generally used as a model system. Consequently we extended our study to protoplasts isolated from $A$. thaliana. We particularly approached the dual localized proteins tp(60)OE33-titin-GFP and tpSSU-titin-GFP. To monitor the dual localization we created fusion proteins with C-terminal PTS1 signal (Figure 5a). This tripeptide directs proteins from the cytosol to peroxisomes $(5,12)$. Indeed, for both proteins, tp(60)OE33titin-GFP-SKL and tpSSU-titin-GFP-SKL, we found a chloroplast localized GFP signal as well as accumulation of GFP fluorescence in specific spots representing peroxisomes (Figure 5b, left and middle panel). On the one hand, the dual localization shows that 60 amino acids are the minimum for sufficient translocation into $A$. thaliana chloroplasts. On the other hand, this shows that the dual localization cannot be competed for by the peroxisomal signal and only proteins accumulating in the cytosol are directed to the latter organelle. In line, all precursor constructs with signals longer than 60 amino acids are efficiently translocated to chloroplasts in A. thaliana protoplasts as exemplified for pSSU-GFP-SKL. For this

(c)
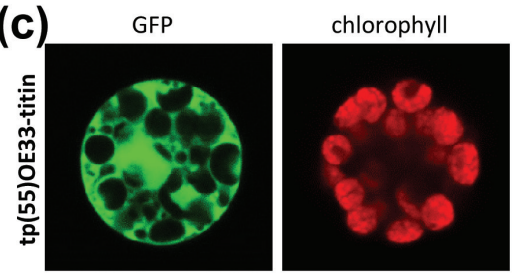

overlay
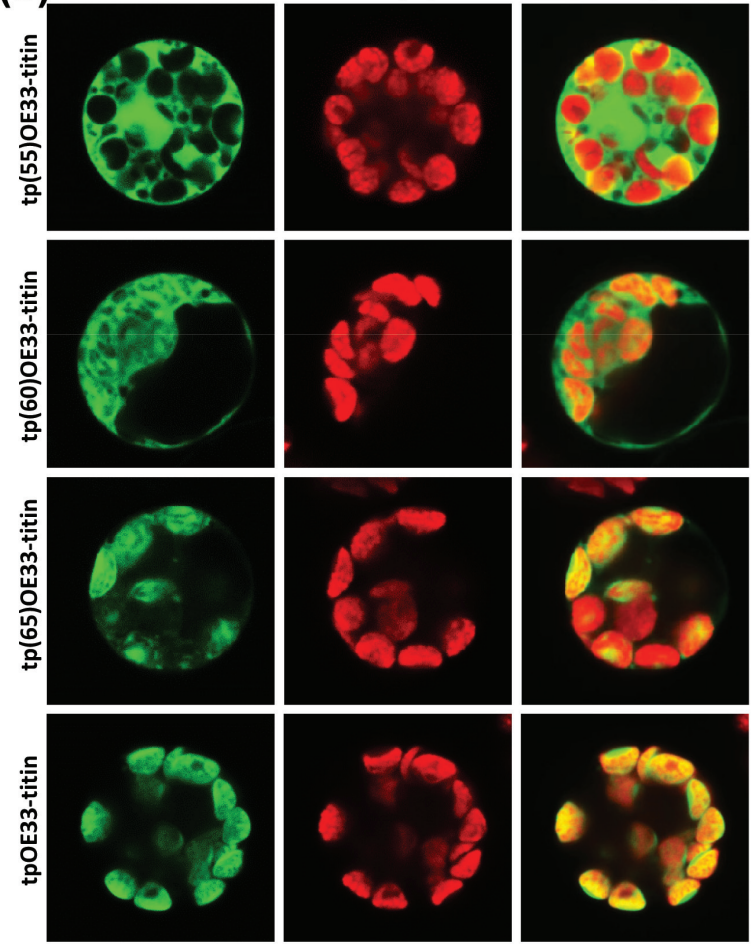

Figure 4. 60 amino acids of the transit peptide of $p O E 33$ are sufficient for preprotein translocation into chloroplasts in vivo. (a) The constructs used are shown as scheme. The transit peptide is shown in blue, the titin domain in black and the GFP domain in green. (b,c) Intracellular distribution of $p O E 33$ constructs in tobacco (b) and tomato (c) protoplasts. Protoplasts were transformed with $p O E 33$-based titin-GFP fusion constructs indicated on the side and analyzed by CLSM after 6 hours of expression. The GFP-fluorescence, the chlorophyll auto-fuorescence and the overlay between GFP-and chlorophyll auto-fluorescence for representative images are shown. 
(a)

(b)
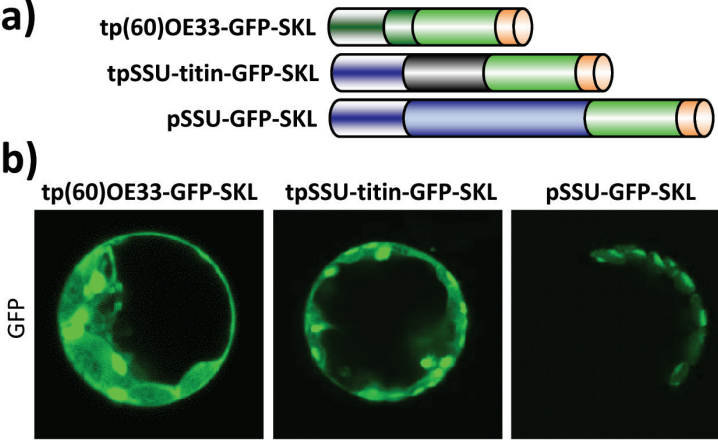

pSSU-GFP-SKL
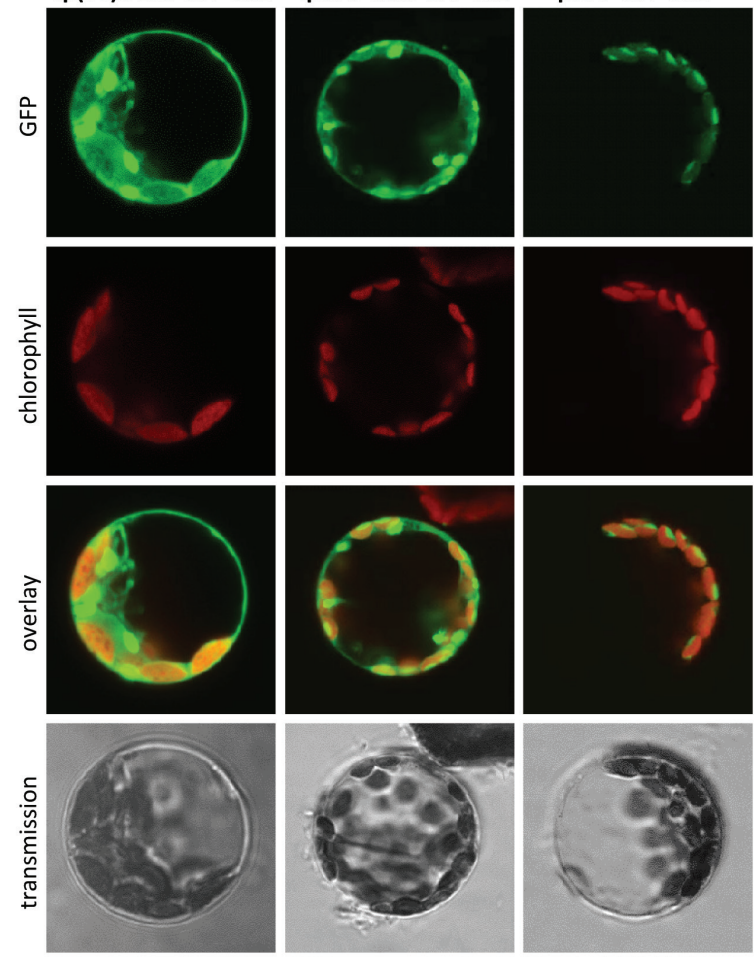

Figure 5. Arabidopsis thaliana displays similar import characteristics like tomato and tobacco. (a) The constructs used are shown as scheme. (b) Arabidopsis thaliana protoplasts were transformed with fusion constructs indicated on top and analyzed by CLSM. The GFP-, chlorophyll auto-fluorescence and the respective overlays are shown along with the transmission channel for representative images.

construct an exclusive GFP localization in chloroplasts was observed (Figure 5b, right panel), which documents that the N-terminal signal for chloroplast targeting overwrites the information for peroxisomal targeting represented by PTS1.

\section{DISCUSSION}

\section{The signal length requirement}

It is accepted that the majority of nuclear encoded chloroplast proteins carry $\mathrm{N}$-terminal transit peptides, which are cleaved off during or after translocation $(2,3,6)$. The signal itself is ill-defined and several reports indicated that elements downstream of the transit peptides can influence the translocation process. For example, import of pFNR (precursor of ferredoxin-NADP+ reductase) is accelerated upon deletion of the first 24 amino acid residues of the mature domain (46), C-terminal truncations of pSSU drastically reduced its import competence (47), while C- terminal deletions of the NADPH/protochlorophyllide oxidoreductase influenced the sorting of the protein inside the chloroplast (48). On the example of the tRNA-NT it was demonstrated that the stability of the mature domain affects the final localization of the dual targeted preprotein as well (49). Further, the transit peptide was found to be essential but not generally sufficient for protein translocation on the examples of pSSU, pFNR, pNTT1, plastocyanin and pOE33 (Figures 1-5; 12,41).

In vitro and in vivo studies (Figures $1-5 ; 12,27,41$ ) document that a length requirement of about 60 amino acid residues exists for translocation into chloroplasts. While small variations might exist between species (e.g. Figure 4) and transit peptides (e.g. Figures 3,4), the concept can be generalized as exemplified for different preproteins and while using protoplasts from different sources (Figures 1-5), Thus, we have to conclude that in the native context a 'signal' of sufficient length appears to be present, irrespective of the position of the processing site. It can be assumed that the preceding region is prone to unfolding if not already unfolded in the preprotein context. Based on the titin fusions, which are not associated with Hsp70 type chaperones in vitro $(12,41)$, the results suggest that an initial intraorganellar 'motor' provides a 'pulling' force of at least $350 \mathrm{pN}$, because a tightly folded titin mutant was imported as efficiently as wild-type titin used herein $(41,43,44)$.

\section{The rationality of the signal length requirement}

The observed length of 60 amino acids raises the question why particularly such length is required for efficient translocation. If one considers that the translocation channel of the chloroplast outer membrane Toc75 belongs to the class of outer membrane proteins annotated as Omp85 (14) the structure of the protein can be approximated from existing structures of the $E$. coli protein of the same family, BamA (50). Moreover, the structures of Toc33/34 (51,52) and of the Hsp70 docking domain of Toc12 have been modeled (35). In addition, the existence of an intermembrane space Hsp70 involved in preprotein translocation has been postulated for a long time $(35,53-$ 55 ) and structural information has been provided for the Hsp70-like DnaK $(56,57)$. The structural information of all described components can be placed into a model to obtain a first estimate on the dimensions during protein translocation (Figure 6). It needs to be mentioned that at stage no structural information exists for Toc159, which contains a $52 \mathrm{kDa}$ domain in the intermembrane space (58) and thus, the dimension of this domain cannot be considered at stage. However, if one places an unfolded polypeptide from receptor side across the translocation channel of the model generated, it becomes obvious that 60 amino acids are just enough to reach from receptor to the Hsp70 docking side (Figure 6). Thus, could this be the stromal chaperone as either Hsp70 (59-61) or Hsp90 (62) are discussed as molecular "motor" in the stroma? 


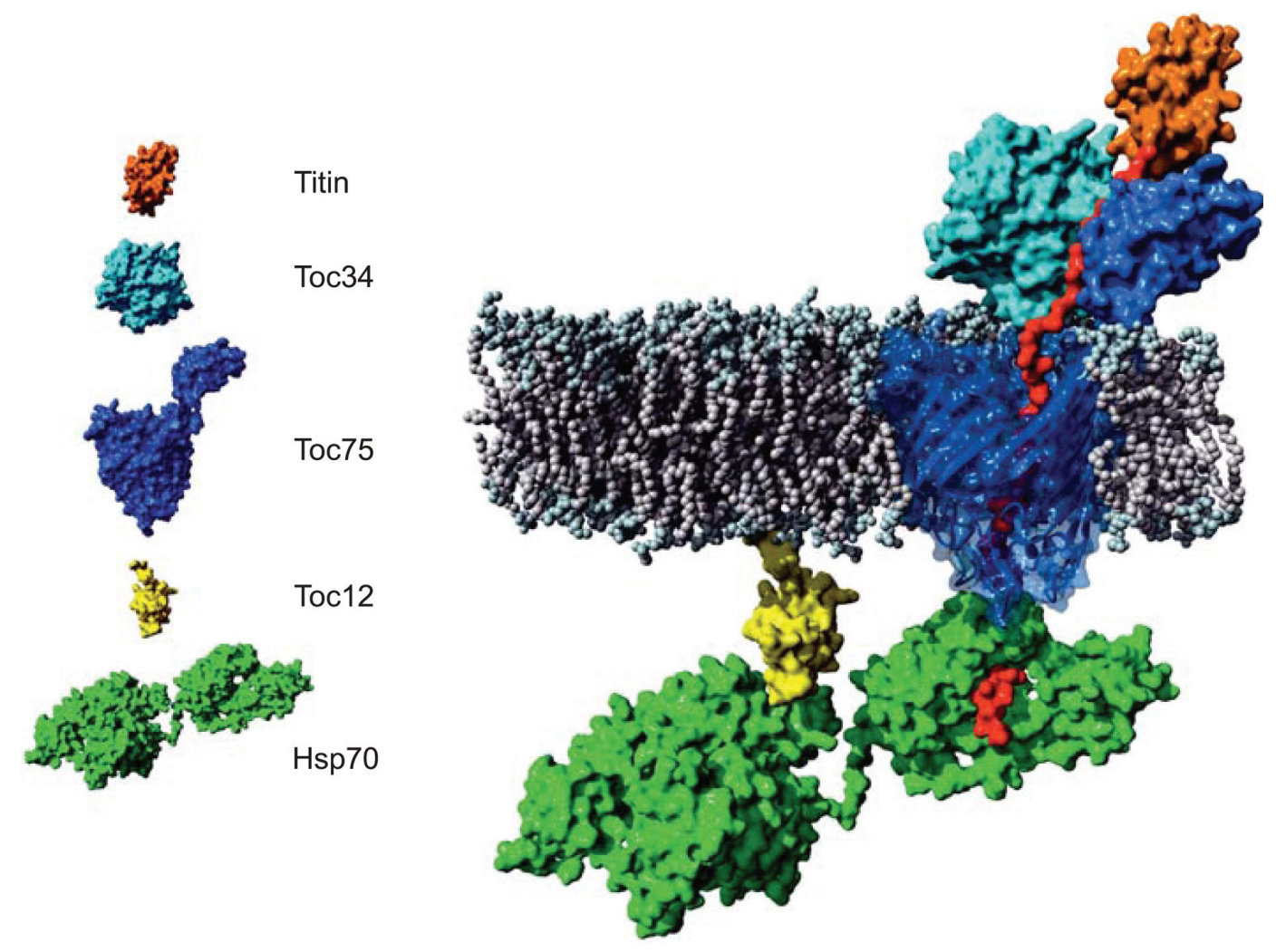

Figure 6. The structural arrangement of domains involved in preprotein translocation. An illustrative model of the components likely to interact with the transit peptide during translocation across the outer envelope is shown. The central translocation pore Toc75 is represented by the crystal structure of BamA including the most C-terminal POTRA domain (blue, 4C4V, 50). The b-barrel was embedded in a membrane of phosphatidylethanolamine lipids. The $G$ domain of Toc33 facing the $C$-terminus toward the membrane (cyan; 3BB3; 51) was placed on the cis side of the translocation pore in close vicinity of the POTRA domain as Toc34-POTRA interaction was observed before (67). The substrate binding domain (SBD) of a model of E. coli Hsp70 bound to DnaJ (green, 2KHO, 56,57) was structurally aligned with the crystal structure of an SBD-peptide complex (1DKZ, 68) to include a substrate peptide. In addition, DnaJ was replaced with a homology model of Toc12 (yellow; 35) and positioned with the N-terminus at the trans side of the membrane. The tp (60)NTT1-titin is represented by the N-terminal 60mer peptide in loose conformation (red) fused to titin (orange, 2RQ8; 69). Note, a multiple sequence alignment of a non-redundant set of $p N T T 1$ homologs revealed a conserved putative Hsp70-binding motif in the N-terminal region (NP_178146, res 8-16, RGLLSLPTK), which contains three leucines flanked by basic amino acids. All molecular modeling was done with YASARA (www.yasara.org) and molecular graphics were rendered with Povray (www.povray.org).

Preproteins contain an Hsp70 binding site within the first 20 amino acids (63), which requires the release of an amino acid stretch of this length from the translocon as shown in the model (Figure 6). Additionally, about 20 amino acids are required to traverse the translocation pore present in the membrane (Figure 6). Thus, if one excludes an intermembrane space molecular "motor" for translocation, more than 40 amino acids would be required to span both, outer and inner membrane in case the two translocation machines tightly interact with each other. However, for the latter no experimental evidence exists. Moreover, the intermembrane space localized $52 \mathrm{kDa}$ domain of Toc159 (58) and the intermembrane space localized C-terminus of Toc33 (note, the Toc33 structure in the model represents the $28 \mathrm{kDa}$ cytosolic domain of the protein; Figure 6) are not shown in the model, because structural information on these domains are not available. The presence of these domains would require additional amino acids of the emerging $\mathrm{N}$-terminus of the preproteins. In addition, the TOC structure observed by electron microscopy $(39,64)$ revealed a dense rim of the TOC complex at the cytosolic side. This high density of domains at the cytosolic side of the TOC complex again argues for the requirement of a certain number of amino acids at the $\mathrm{N}$-terminus of the preproteins before the signal enters the outer membrane pore.

Thus, as exemplified in the model, the observed requirement of 60 amino acids cannot be explained by a direct contact to the energizing machinery in the stroma, but fits very well with the dimensions assumed for the TOC translocon (Figure 6). This conclusion based on structural estimations is supported by experimental evidence, as it was documented that an intermembrane space-localized ATPase is involved in protein transloca- 
tion (65), and the stromal chaperone system does not provide an unfolding capacity (66) that would be required to translocate preproteins with the tightly folded titin passenger (Figures1-6; 12,41). Summing up, the identified requirement of 60 amino acids in a loosely folded state for efficient import in vivo can only be explained by the existence of an ATP-consuming molecular motor, most likely presented by the long time postulated intermembrane space Hsp70.

Acknowledgements: A model of E. coli Hsp70 bound to DnaJ was kindly provided by Erik Zuiderweg (University Michigan). This project was funded by the Cluster of Excellence Frankfurt "Macromolecular Complexes" and by the Deutsche Forschungsgemeinschaft in project DFG SCHL 585-3 and in the frame of SFB807/P17.

\section{REFERENCES}

1. SCHATZ G, DOBERSTEIN B (1996) Common principles of protein translocation across membranes. Science 271: 1519-1526. http://dx.doi.org/10.1126/science.271.5255.1519

2. SCHLEIFF E 2000 Signals and receptors, the translocation machinery on the mitochondrial surface. J Bioenerg Biomem 32: 55-66. http://dx.doi.org/10.1023/A:1005512412404

3. SCHLEIFF E, SOLL J 2000 Traveling of proteins through membranes: Translocation into chloroplasts. Planta 211: 449-456. http:// dx.doi.org/10.1007/s004250000357

4. W. GIRZALSKY W, PLATTA HW; ERDMANN R 2009 Protein transport across the peroxisomal membrane. Biol Chem 390: 745751.

5. GOULD SJ, KELLER GA, HOSKEN N, WILKINSON J, SUBRAMANI S 1989 A conserved tripeptide sorts proteins to peroxisomes. J Cell Biol 108: 1657-1664. http://dx.doi.org/10.1083/ jcb.108.5.1657

6. SCHLEIFF E, BECKER T 2011, Common ground for protein translocation: access control for mitochondria and chloroplasts. Nat Rev Mol Cell Biol 12: 48-59. http://dx.doi.org/10.1038/nrm3027

7. KARLIN-NEUMANN GA, TOBIN EM 1986 Transit peptides of nuclear-encoded chloroplast proteins share a common amino acid framework. $E M B O J$ 5: 9-13.

8. VON HEIJNE G, STEPPUHN J; HERMANN RG 1989 Domain structure of mitochondrial and chloroplast targeting peptides. Eur JBiochem 180:535-545. http://dx.doi.org/10.1111/j.1432-1033.1989. tb14679.x

9. ZYBAILOV B, RUTSCHOW H, FRISO G, RUDELLA A, EMANUELSSON O, SUN Q, VAN WIJK KJ 2008 Sorting signals, N-terminal modifications and abundance of the chloroplast proteome. PLoS One. 3: e1994.

10. TENG YS, CHAN PT, LI HM 2012 Differential age-dependent import regulation by signal peptides. PLoS Biol 10: e1001416. http://dx.doi.org/10.1371/journal.pbio.1001416

11. ZHANG XP; GLASER E 2002 Interaction of plant mitochondrial and chloroplast signal peptides with the Hsp70 molecular chaperone. Trends Plant Sci. 7: 14-21.

12. BIONDA T, TILLMANN B, SIMM S; BEILSETIN K, RUPRECHT M, SCHLEIFF E 2010 Chloroplast import signals: the length requirement for translocation in vitro and in vivo. J Mol Biol 402: 510-523. http://dx.doi.org/10.1016/j.jmb.2010.07.052

13. MIRUS O, SCHLEIFF E 2012 Recycling and Tinkering- The evolution of protein transport to and into endosymbiotically derived organelles. In: Organelle Genetics: Evolution of organelle genomes and gene expression (Ed. E. C.E. Bullerwell), Springer Verlag Berlin, pp 175-216. http://dx.doi.org/10.1007/978-3-642-22380-8_8

14. LÖFFELHARDT WA, VON HAESELER, SCHLEIFF E 2007 The b-barrel shaped polypeptide transporter, an old concept for precursor protein transfer across membranes. Symbiosis. 44: 33-42.

15. STRUYVE M, MOONS M, TOMMASSEN J. 1991 Carboxyterminal phenylalanine is essential for the correct assembly of a bacterial outer membrane protein. J Mol Biol 218: 141-148. http:// dx.doi.org/10.1016/0022-2836(91)90880-F

16. HARB OS, CHATTERJEE B, FRAUNHOLZ MJ, CRAWFORD MJ, NISHI M, ROOS DS, 2004 Multiple functionally redundant signals mediate targeting to the apicoplast in the picomplexan parasite Toxoplasma gondii. Eukaryotic Cell 3: 663-674. http:// dx.doi.org/10.1128/EC.3.3.663-674.2004

17. GOULD SB, OMMER MS, HADFI K, ZAUNER S, KROTH PG, MAIER UG 2006 Protein targeting into the complex plastid of cryptophytes. J. Mol. Evol. 62: 674-681. http://dx.doi. org/10.1007/s00239-005-0099-y

18. GRUBER A, VUGRINEC S, HEMPEL F, GOULD SB, MAIER UG, KROTH PG 2007 Protein targeting into complex diatom plastids:functional characterization of a specific targeting motif. Plant Mol. Biol. 64: 519-530. http://dx.doi.org/10.1007/s11103007-9171-x

19. PATRON NJ, WALLER RF 2007 Transit peptide diversity and divergence: A global analysis of plastid targeting signals. Bioessays 29: 1048-1058. http://dx.doi.org/10.1002/bies.20638

20. RALPH SA, FOTH BJ, HALL N, McFADDEN GI 2004 Evolutionary pressures on apicoplast transit peptides. Mol Biol Evol 21: 2183-2194. http://dx.doi.org/10.1093/molbev/msh233

21. STEINER JM, YUSA F, POMPE JP, LÖFFELHARDT W 2005 Homologous protein import machineries in chloroplasts and cyanelles. Plant J 44: 646-652. http://dx.doi. org/10.1111/j.1365-313X.2005.02559.x

22. WUNDER T, MARTIN R, LÖFFELHARDT W, SCHLEIFF E, STEINER JM 2007 The invariant phenylalanine of precursor proteins discloses the importance of Omp85 for protein translocation into cyanelles. BMC Evol Biol 7:236. http://dx.doi.org/10.1186/14712148-7-236

23. LIAUD MF, ZHANG DX, CERFF R 1990 Differential intron loss and endosymbiotic transfer of chloroplast glyceraldehyde-3-phosphate dehydrogenase genes to the nucleus. Proc Natl Acad Sci USA 87: 8918-8922. http://dx.doi.org/10.1073/pnas.87.22.8918

24. LONG M, DE SOUZA SJ, ROSENBERG C, GILBERT W 1996 Exon shuffling and the origin of the mitochondrial targeting function in plant cytochrome c1 precursor. Proc Natl Acad Sci USA 93: 7727-7731. http://dx.doi.org/10.1073/pnas.93.15.7727

25. GREGERSON RG, MILLER SS, PETROWSKI M, GANTT JS, VANCE CP 1994 Genomic structure, expression and evolution of the alfalfa aspartate aminotransferase genes. Plant Mol Biol 25: 387399. http://dx.doi.org/10.1007/BF00043868

26. QUIGLEY F, MARTIN WF, CERFF R 1988 Intron conservation across the prokaryote-eukaryote boundary: structure of the nuclear gene for chloroplast glyceraldehyde-3-phosphate dehydrogenase from maize. Proc Natl Acad Sci USA 85: 2672-2676. http://dx.doi. org/10.1073/pnas.85.8.2672

27. ROLLAND N., JOB D, DOUCE R 1993 Common sequence motifs coding for higher-plant and prokaryotic O-acetylserine (thiol)lyases: bacterial origin of a chloroplast transit peptide? Biochem J 293: 829-833. http://dx.doi.org/10.1042/bj2930829

28. VOJTA A, FULGOSI H, SCHLEIFF E 2008 The molecular concept of protein translocation across the outer membrane of chloroplasts. Croat Chem Acta 81: 501-509.

29. SOLL J, SCHLEIFF E 2004 Protein import into chloroplasts. $\mathrm{Na}$ ture Reviews: Mol Cell Biol 5: 198-208. http://dx.doi.org/10.1038/ nrm1333 
30. SCHLEGEL T, MIRUS O, VON HAESELER, SCHLEIFF E 2007 The tetratricopeptide repeats of receptors involved in protein translocation across membranes. Mol Biol Evol 24: 2763-2774. http://dx.doi.org/10.1093/molbev/msm211

31. QBADOU S, BECKER T, MIRUS O, TEWS I, SOLL J SCHLEIFF E 2006 The molecular chaperone Hsp90 delivers precursor proteins to the chloroplast import receptor Toc64. EMBO J. 25: 18361847.

32. MIRUS O, BIONDA T, VON HAESELER A, SCHLEIFF E 2009 Evolutionarily evolved discriminators in the 3-TPR domain of the Toc64 family involved in protein translocation at the outer membrane of chloroplasts and mitochondria. J Mol Model 15: 971-982. http://dx.doi.org/10.1007/s00894-008-0449-y

33. SOMMER M, RUDOLF M, TILLMANN B, TRIPP J, SOMMER MS, SCHLEIFF E 2013 Toc33 and Toc64-III cooperate in precursor protein import into the chloroplasts of Arabidopsis thaliana. Plant Cell Environ 36: 970-983. http://dx.doi.org/10.1111/pce.12030

34. QBADOU S, BECKER T, BIONDA T, REGER K, RUPRECHT M, SOLL J, SCHLEIFF E 2007 Toc64-a preprotein-receptor at the outer membrane with bipartide function. J Mol Biol 367: 1330-1346. http://dx.doi.org/10.1016/j.jmb.2007.01.047

35. BECKER T, HRITZ J, VOGEL M, CALIEBE A, BUKAU B, SOLL J; SCHLEIFF E 2004 Toc12, a novel subunit of the intermembrane space preprotein translocon of chloroplasts. Mol Biol Cell 15: 5130-5144. http://dx.doi.org/10.1091/mbc.E04-05-0405

36. KOURANOV A, CHEN X, FUKS B, SCHNELL DJ 1998, Tic20 and Tic22 are new components of the protein import apparatus at the chloroplast inner envelope membrane. J Cell Biol 143: 991-1002.

37. TRIPP J, HAHN A, KOENIG P, FLINNER N, BUBLAK D, BROUWER EM, ERTEL F, MIRUS O, SINNING I, TEWS I, SCHLEIFF E 2012 Structure and conservation of the periplasmic targeting factor Tic22 protein from plants and cyanobacteria.J Biol Chem 287: 24164-24173.

38. RUDOLF M, MACHETTIRA AB, GROß AB, WEBER KL, BOLTE K, BIONDA T, SOMMER MS, MAIER UG, WEBER AP, SCHLEIFF E, TRIPP J 2013 In vivo function of Tic22, a protein import component of the intermembrane space of chloroplasts. Mol Plant 6: 817-829.

39. SOMMER MS, DAUM B, GROSS LE, WEIS BL,, MIRUS O, AABRAM L, MAIER UG, KÜHLBRANDT W, SCHLEIFF E 2011 Chloroplast Omp85 proteins change orientation during evolution. Proc Natl Acad Sci USA 108: 13841-13846. http://dx.doi. org/10.1073/pnas.1108626108

40. MISHRA SK, TRIPP J, WINKELHAUS S, TSCHIERSCH B, THERES K, NOVER L, SCHARF KD 2002 In the complex family of heat stress transcription factors, HsfA1 has a unique role as master regulator of thermotolerance in tomato. Genes Dev 16: 15551567. http://dx.doi.org/10.1101/gad.228802

41. RUPRECHT M, BIONDA T, SATO T, SOMMER MS, ENDO T, SCHLEIFF E 2010 On the impact of precursor unfolding during protein import into chloroplasts. Mol Plant 3: 499-508. http://dx. doi.org $/ 10.1093 / \mathrm{mp} / \mathrm{ssp} 116$

42. SATO T, ESAKI M, FERNANDEZ JM, ENDO T 2005 Comparison of the protein-unfolding pathways between mitochondrial protein import and atomic-force microscopy measurements. Proc Natl Acad Sci USA 102: 17999-18004. http://dx.doi.org/10.1073/ pnas.0504495102

43. LI H, CARRION- VAZQUEZ M, OBERHAUSER AF, MARSZALEK PE, FERNANDEZ JM 2000 Point mutations alter the mechanical stability of immunoglobulin modules. Nat Struct Biol 7: 1117-1120.

44. BROCKWELL DJ, BEDDARD GS, CLARKSON J, ZINOBER RC, BLAKE AW, TRINICK J, OLMSTED PD, SMITH DA, RADFORD SE 2002 The effect of core destabilization on the mechanical resistance of I27. Biophys J 83: 458-472. http://dx.doi. org/10.1016/S0006-3495(02)75182-5
45. KMIEC-WISNIEWSKA B, KRUMPE K, URANTOWKA A, SAKAMOTO W, PRATJE E, JANSKA H 2008 Plant mitochondrial rhomboid, AtRBL12, has different substrate specificity from its yeast counterpart. Plant Mol Biol 68: 159-171. http://dx.doi. org/10.1007/s11103-008-9359-8

46. RIAL DV, LOMBARDO VA, CECCARELLI EA, OTTADO J 2002 The import of ferredoxin-NADP+reductase precursor into chloroplasts is modulated by the region between the transit peptide and the mature core of the protein. Eur J Biochem 269: 5431-5439. http://dx.doi.org/10.1046/j.1432-1033.2002.03233.x

47. DABNEY-SMITH C, VAN DEN WIJNGAARD PW, TREECE Y, VREDENBERG WJ, BRUCE BD 1999, The C terminus of a chloroplast precursor modulates its interaction with the translocation apparatus and PIRAC. J Biol Chem 274: 32351-32359. http://dx.doi. org/10.1074/jbc.274.45.32351

48. ARONSSON H; SUNDQVIST C, TIMKO MP, DAHLIN C 2001 The importance of the $\mathrm{C}$-terminal region and Cys residues for the membrane association of the NADPH:protochlorophyllide oxidoreductase in pea. FEBS Lett 502: 11-15. http://dx.doi.org/10.1016/ S0014-5793(01)02595-9

49. LEIBOVITCH M, BUBLAK D, HANIC-JOYCE PJ, TILLMANN B, FLINNER N, AMSEL D, SCHARF KD, MIRUS O, JOYCE PB, SCHLEIFF E 2013 The folding capacity of the mature domain of the dual-targeted plant tRNA nucleotidyltransferase influences organelle selection. Biochem J 453: 401-412. http://dx.doi. org/10.1042/BJ20121577

50. R. ALABRECHT R, SCHÜTZ M, OBERHETTINGER P, FAULSTICH M, BERMEJO I; RUDEL T; DIEDERICHS K; ZETH K 2014 Structure of BamA, an essential factor in outer membrane protein biogenesis. Acta Crystallogr D Biol Crystallogr 70: 17791789

51. KOENIG P, OREB M, HÖFLE A., KALTOFEN S, RIPPE K, SINNING I, SCHLEIFF E, TEWS I 2008 The GTPase cycle of the chloroplast import receptors Toc33/Toc34 - Implications from monomeric and dimeric structures. Structure 16:585-596. http://dx.doi. org/10.1016/j.str.2008.01.008

52. KOENIG P, OREB M, RIPPE K, MUHLE-GOLL C, SINNING I, SCHLEIFF E, TEWS I 2008 On the significance of Toc-GTPase homodimers. J Biol Chem 283: 23104-23112. http://dx.doi. org/10.1074/jbc.M710576200

53. MARSHALL JS, DeROCHER AE, KEEGSTRA K, VIERLING E 1990 Identification of heat shock protein hsp70 homologues in chloroplasts. Proc Natl Acad Sci USA 87: 374-378. http://dx.doi. org/10.1073/pnas.87.1.374

54. WAEGEMANN K; SOLL J 1991 Characterization of the protein import apparatus in isolated outer envelopes of chloroplasts. Plant J. 1: 149-158. http://dx.doi.org/10.1111/j.1365-313X.1991.00149.x

55. SCHNELL DJ, KESSLER F, BLOBEL G 1994 Isolation of components of the chloroplast protein import machinery. Science. 266 : 1007-1012. http://dx.doi.org/10.1126/science.7973649

56. A. AHMAD A; BHATTACHARYA A, McDONAKD RA, CORDES M, ELLINGTON B, BERTELSEN EB, E. R. ZUIDERWEG ER 2011 Heat shock protein $70 \mathrm{kDa}$ chaperone/DnaJ cochaperone complex employs an unusual dynamic interface. Proc Natl Acad Sci USA. 108: 18966-18971.

57. BERTELSEN EB, CHANG L, GESTWICKI JE; ZUIDERWEG ER 2009 Solution conformation of wild-type E. coli Hsp70 (DnaK) chaperone complexed with ADP and substrate. Proc Natl Acad Sci USA 106: 8471-8476.

58. BECKER T, JELIC M, VOJTA A, SOLL J, SCHLEIFF E 2004 The mode of preprotein recognition by the Toc machinery. EMBO J. 23: 520-530. http://dx.doi.org/10.1038/sj.emboj.7600089

59. LIU L, McNEILAGE RT, SHI LX, Theg SM 2014 ATP requirement for chloroplast protein import is set by the Km for ATP hydrolysis of stromal Hsp70 in Physcomitrella patens. Plant Cell 26: 12461255. http://dx.doi.org/10.1105/tpc.113.121822 
60. SHI LX, THEG SM, 2010, A stromal heat shock protein 70 system functions in protein import into chloroplasts in the moss Physcomitrella patens. Plant Cell. 22: 205-220. http://dx.doi.org/10.1105/ tpc.109.071464

61. SU PH, LI HM 2010 Stromal Hsp70 is important for protein translocation into pea and Arabidopsis chloroplasts. Plant Cell 22: 15161531. http://dx.doi.org/10.1105/tpc.109.071415

62. INOUE H, LM; SCHNELL DJ 2013 An essential role for chloroplast heat shock protein 90 (Hsp90C) in protein import into chloroplasts. Proc Natl Acad Sci USA. 110: 3173-3178.

63. IVEY 3rd RA, SUBRAMANIAN C, BRUCE BD 2000 Identification of a Hsp70 recognition domain within the rubisco small subunit transit peptide. Plant Physiol 122: 1289-1299.

64. SCHLEIFF E, SOLL J, KÜCHLER M, KÜHLBRANDT W, HARRER R. 2003 Characterisation of the translocon of the outer envelope of chloroplasts. J Cell Biol 160: 541-551. http://dx.doi. org/10.1083/jcb.200210060

65. OLSEN LJ, KEEGSTRA K 1992 The binding of precursor proteins to chloroplasts requires nucleoside triphosphates in the intermembrane space. J Biol Chem 267: 433-439.
66. KOVACHEVA S, BEDARD J, WARDLE A, PATEL R, JARVIS P 2007 Further in vivo studies on the role of the molecular chaperone, Hsp93, in plastid protein import. Plant J. 50:364-379. http://dx.doi. org/10.1111/j.1365-313X.2007.03060.x

67. ERTEL F, MIRUS O, BREDEMEIER R, MOSLAVAC S, BECKER T, SCHLEIFF E 2005 The evolutionary related B-barrel polypeptide transporters from P. sativum and Nostoc PCC7120 contain two distinct functional domains. J Biol Chem 280: 28281-28289. http://dx.doi.org/10.1074/jbc.M503035200

68. ZHU X, ZHAO X, BURKHOLDER WF, GRAGEROV A, OGATA CM, GOTTESMANN ME,. HENDRICKSON WA 1996 Structural analysis of substrate binding by the molecular chaperone DnaK. Science. 272: 1606-1614. http://dx.doi.org/10.1126/science.272.5268.1606

69. YAGAWA K, YANANO K, OGURO T, MAEDA M, SATO T, MOMOSE T, KAWANO S, ENDO T 2010 Structural basis for unfolding pathway-dependent stability of proteins: vectorial unfolding versus global unfolding. Protein Sci 19: 693-702. http://dx.doi. org/10.1002/pro.346 